Communication Journal of Pharmacy and Pharmacology

\title{
Absorption of phenolsulfonphthalein as a model across the mesenteric surface in rats to determine the drug absorption route after intraperitoneal administration
}

Koyo Nishida, Seiichi Nose, Akiko Kuma, Takahiro Mukai, Mikiro Nakashima, Hitoshi Sasaki and Junzo Nakamura

Department of Clinical Pharmacy, Graduate School of Biomedical Sciences, Nagasaki University, 1-14 Bunkyo-machi, Nagasaki 852-8521, Japan

K. Nishida, S. Nose, A. Kuma, T. Mukai, J. Nakamura

Department of Hospital Pharmacy, Nagasaki University School of Medicine, 1-7-1

Sakamoto, Nagasaki 852-8501, Japan

M. Nakashima, H. Sasaki

Correspondence: K. Nishida, Department of Clinical Pharmacy, Graduate School of Biomedical Sciences, Nagasaki University, 1-14 Bunkyo-machi, Nagasaki 852-8521, Japan. E-mail: koyo-n@net.nagasaki-u.ac.jp

Shortened title: Drug absorption from mesenteric surface 


\section{Abstract}

The purpose of this study is to clarify absorption characteristics of a drug across the mesenteric surface which occupies a large area of absorption in the peritoneal cavity in order to determine the drug absorption route after intraperitoneal administration. Absorption of phenolsulfonphthalein (PSP) as a model after application to the mesenteric surface was investigated in rats, by employing a cylindrical diffusion cell attached to the mesentery with or without blood vessels. PSP was absorbed from the rat mesenteric surface, followed by its appearance in the plasma and bile, regardless of blood vessel existence. The absorption ratios of PSP in $6 \mathrm{~h}$ were calculated to be $92.1 \%$ and $83.6 \%$ from the mesenteric surface with and without blood vessels, respectively. We then employed an experimental system by sticking a polyethylene cap (PE cap) on the surface of the other side to exclude the influence of absorption of the drug from the other organ surfaces that penetrated across the mesentery. The PE cap-sticking decreased the appearance of PSP in the plasma from the mesenteric surface with blood vessels and eliminated the PSP absorption completely from the mesenteric surface without blood vessels. Accordingly, blood vessels on the mesenteric surface actually play an important role in drug absorption, but the contribution of the mesenteric surface to drug absorption from the peritoneal cavity is unlikely to be significant due to there being a small effective area of blood vessels. 


\section{Introduction}

The peritoneal cavity is a potential space for peritoneal dialysis as a long-term renal replacement therapy and intraperitoneal (i.p.) chemotherapy of cancer restricted to the peritoneal cavity (e.g. ovarian carcinoma). The effects of molecular weight (Dedrick et al 1978; Litterst et al 1982), charge (Lukas et al 1971) and injection volume (Barrett et al 1991; Bredberg et al 1994) on drug absorption after i.p. administration have been reported. Although the i.p. route of drugs has attracted attention, it has not been fully clarified whether drug absorption from the peritoneal cavity occurs through the specific organs. We previously examined the absorption characteristics of several compounds from the liver surface (Nishida et al 1994, 1995a-b, 1996, 1997), kidney surface (Kawakami et al 2002; Nakamura et al 2003), serosal gastric surface (Mukai et al 1999; Nakamura et al 1999) and serosal caecal surface (Nishida et al 2002) in rats in a series of investigations.

In the peritoneal cavity, mesentery is well developed and likely plays an important role in peritoneal drug transport due to its large surface area. The mesentery with blood vessels and lymph ducts is a fold of the peritoneum attaching the stomach, small intestine and other organs to the posterior wall of the abdomen. The absorption mechanism from the mesenteric surface needs to be examined in order to estimate in-vivo absorption of a drug after i.p. administration in humans by extrapolating the animal data. However, the contribution of the mesentery to peritoneal drug absorption still remains obscure.

In the present study, we investigated the absorption of the organic anion phenolsulfonphthalein as a model after its application to the rat mesenteric surface. Moreover, we examined the influence of blood vessel existence and blocks of peritoneal diffusion on the absorption across the mesenteric surface. 


\section{Materials and methods}

\section{Chemicals}

Phenolsulfonphthalein (PSP) was purchased from Nacalai Tesque, Inc. (Kyoto, Japan). other chemicals were of reagent grade.

\section{In-vivo experiment}

All animal experiments in the present study conformed to the Guideline for Animal Experimentation in Nagasaki University.

Male Wistar rats (250-316 g) were housed in cages in an air-conditioned room and maintained on standard rat foods and water freely available. The left femoral artery and common bile duct of the rats were anaesthetized with sodium pentobarbitone (50 mg kg-1, i.p.) and cannulated with polyethylene tubes. A cylindrical diffusion cell (i.d. $6 \mathrm{~mm}$, area $0.28 \mathrm{~cm}^{2}$ ) was attached to the rat mesenteric surface with or without blood vessels by the adhesive chemical Aron Alpha (Sankyo Co. Ltd., Tokyo, Japan). The in-vivo experiments were performed under closed cavity conditions except for the region where the diffusion cell was attached. A schematic drawing outlining the in-vivo experiment is illustrated in Figure 1. To exclude the influence of drug absorption from the other organ surfaces after penetration across the mesentery in the peritoneal cavity, we employed an experimental system by sticking a polyethylene cap (PE cap) on the surface of the other side attached to a diffusion cell, as shown in Figure 1.

One mg of PSP was dissolved in $0.05 \mathrm{~mL}$ of isotonic phosphate buffer (pH 7.4) and added to the diffusion cell directly. After application of PSP to the rat mesenteric surface, the plasma, bile, urine and solution remaining in the diffusion cell were sampled at specified times.

\section{Analytical methods}

The concentrations of PSP in the plasma, bile, urine and solution remaining in the diffusion 
cell were determined as follows. The concentration of free PSP was determined spectrophotometrically at $560 \mathrm{~nm}$ after dilution with $1 \mathrm{M} \mathrm{NaOH}$. The total concentration of free PSP and its metabolite was measured in the same manner after they were subjected to acid hydrolysis (2 $\mathrm{M} \mathrm{HCl}$ at $100^{\circ} \mathrm{C}$ for $30 \mathrm{~min}$ ) (Hart and Schanker 1966). The concentration of PSP metabolite (glucuronic acid conjugate) was estimated from the difference between these values. PSP metabolite could not be detected in the plasma. The accuracy of the PSP assay was guaranteed by correlation coefficient of calibration curve $\left(\mathrm{r}^{2}>0.998\right)$ and the detection limit was $0.01 \mu \mathrm{g} \mathrm{mL} \mathrm{m}^{-1}$.

\section{Calculation of moment parameters}

The plasma concentration profile of free PSP and biliary excretion rate profiles of free PSP and its metabolite were analyzed based on the statistical moment theory. Statistical moment theory has been used to calculate overall parameters to evaluate drug absorbability. Moment parameters for a plasma concentration profile of free PSP (AUC, $\left.\mathrm{MRT}_{\mathrm{p}}\right)$ and those for biliary excretion rate profiles of free PSP $\left(\mathrm{AUC}_{\mathrm{b}, \mathrm{f}}, \mathrm{MRT}_{\mathrm{b}, \mathrm{f}}\right)$ and its metabolite $\left(\mathrm{AUC}_{\mathrm{b}, \mathrm{m}}\right.$, $\mathrm{MRT}_{\mathrm{b}, \mathrm{m}}$ ) were calculated using a linear trapezoidal formula and extrapolation to infinite time based on a monoexponential equation (Yamaoka et al 1978).

\section{Statistical analysis}

Statistical analysis was performed by applying a 2-way ANOVA, followed by post hoc Tukey's test. $\quad P<0.05$ was considered to be statistically significant. All values were expressed as the mean value \pm standard error (s.e.) of at least four experiments.

\section{Results and discussion}

We have established an experimental system utilizing a cylindrical diffusion cell attached to the rat mesenteric surface. This experimental system enables us to examine drug 
absorption from the mesenteric surface without interference by absorption from the other sites. We selected hydrophilic dye PSP as a model, because its absorption from several organ surfaces has been well characterized (Nishida et al 1994, 1995a-b, 1997, 2002; Nakamura et al 1999; Mukai et al 1999). In addition, PSP disposition characteristics have been investigated previously (Enna and Schanker 1973; Nishida et al 1989; Kakutani et al 1992).

\section{Absorption of PSP across the mesenteric surface in rats}

The mesenteric vascular system is so developed that absorption from the blood vessel surface should be relatively good. Therefore, we assessed drug absorption from the mesenteric surface with or without blood vessels, and attached a diffusion cell to each region of rat mesenteric surface as illustrated in Figure 1.

Figures 2A and 2B show the plasma concentration profile of free PSP after application to the rat mesenteric surface without or with blood vessels at a dose of $1 \mathrm{mg}$, respectively. The PSP that appeared in the plasma reached maximum $1 \mathrm{~h}$ after dosing, suggesting the occurrence of drug absorption from the rat mesenteric surface regardless of blood vessel existence. After absorption from the rat mesenteric surface without or with blood vessels, free PSP was excreted into the bile as shown in Figures 3A and 3B. The metabolite of PSP (glucuronic acid conjugate) was also excreted into the bile (Figures 3A and 3B). The absorption ratios of PSP in $6 \mathrm{~h}$ calculated from the PSP amount remaining in the diffusion cell were not significantly different $(92.1 \%$ and $83.6 \%$, with and without blood vessels, respectively) (Table 1). Accordingly, good absorption of PSP from the mesenteric surface was demonstrated, although PSP is poorly absorbed from the gastrointestinal mucosa because it is highly ionized and has a very small partition coefficient at physiological pH (Schanker et al 1958).

\section{Diffusion into the peritoneal cavity of PSP penetrated across the mesentery}

Rapid absorption of PSP was recognized (Figures 2A and 2B) regardless of blood vessel 
existence on the mesenteric surface of the rats. However, we observed the penetration of PSP through the mesentery in the case of attaching a diffusion cell on the rat mesentery invitro (data not shown). This implies the possibility that the administered PSP penetrates the mesentery, followed by absorption from the other organ surfaces in the peritoneal cavity. Therefore, the diffusion into the peritoneal cavity of PSP that penetrates through the mesenteric surface must be removed to evaluate precisely the absorption only from the mesenteric surface. We employed an experimental system by sticking a PE cap on the surface of the other side of the mesentery attached to the diffusion cell to inhibit drug diffusion into the peritoneal cavity (Figure 1).

In the experiment using a PE cap for the mesenteric surface with blood vessels, the plasma concentrations of PSP decreased (Figure 2B). On the other hand, the appearance of PSP in the plasma disappeared completely on account of the PE cap after application to the rat mesenteric surface without blood vessels (Figure 2A). Similar tendencies were observed with the biliary excretion rate profiles of free PSP and its metabolite (Figures 3A and 3B). As listed in Table 1, the absorption ratios of PSP were high with or without blood vessels in the experiment attached with only a diffusion cell to the rat mesenteric surface. However, the PE cap-sticking method significantly decreased the absorption ratio of PSP to $8.3 \%(P<$ 0.01) without blood vessels (Table 1). In addition, the absorption ratio of PSP was decreased to $66.9 \%$ with blood vessels, although the difference was not significant. The biliary and urinary excretion of free PSP and its metabolite also decreased according to the reduction in absorption, and they were not detected after absorption from the mesenteric surface without blood vessels. Accordingly, these results imply that most of the PSP that penetrated through the mesentery was absorbed from the other organ surfaces in the experimental system attached only to a diffusion cell. Consequently, it appears that blood vessels on the mesentery surface actually play an important role in drug absorption, and that 
contribution of the mesenteric surface to drug absorption from the peritoneal cavity is not marked because of the small effective area of blood vessels.

The overall absorption and excretion processes can be evaluated with moment parameters with regard to extent and rate. Table 2 lists the moment parameters for the plasma concentration profiles of free PSP and biliary excretion rate profiles of free PSP and its metabolite. A decrease was observed in the $\mathrm{AUC}_{\mathrm{p}}, \mathrm{AUC}_{\mathrm{b}, \mathrm{f}}$, and $\mathrm{AUC}_{\mathrm{b}, \mathrm{m}}$ by sticking the $\mathrm{PE}$ cap on the surface of the other side of the mesentery with blood vessels. After application to the mesentery without blood vessel the $\mathrm{MRT}_{\mathrm{p}}(220.2 \mathrm{~min})$ was longer than that of the blood vessels and PE cap (171.9 min), representing the time necessary for absorption from the other organ surfaces after penetration through the mesenteric surface (Table 2).

In conclusion, the mesenteric surface itself does not contribute to PSP absorption, and absorption could mostly result from the blood vessel on the mesenteric surface. The present results should provide us useful information in determining the drug absorption across the mesentery.

\section{Acknowledgements and funding:}

We thank Rika Tsuwamoto for skilled technical assistance. This work was supported in part by a Grant-in-Aid for Scientific Research from the Ministry of Education, Culture, Sports, Science and Technology, Japan. 


\section{References}

Barrett, J. S., Wagner, J. G., Fisher, S. J., Wahl, R. L. (1991) Effect of intraperitoneal injection volume and antibody protein dose on the pharmacokinetics of intraperitoneally administered IgG2a kappa murine monoclonal antibody in the rat. Cancer Res. 51: 34343444

Bredberg, E., Lennernas, H., Paalzow, L. (1994) Pharmacokinetics of levodopa and carbidopa in rats following different routes of administration. Pharm. Res. 11: 549-555

Dedrick, R. L., Myers, C. E., Bungay, P. M., DeVita Jr, V. T. (1978) Pharmacokinetic rationale for peritoneal drug administration in the treatment of ovarian cancer. Cancer Treat. Rep. 62: $1-11$

Enna, S. J., Schanker, L. S. (1973) Phenol red absorption from the rat lung: evidence of carrier transport. Life Sci. 12: 231-239

Hart, L. G., Schanker, L. S. (1966) The chemical forms in which phenol red is secreted into the bile of rats. Proc. Soc. Exp. Biol. Med. 123: 433-435

Kakutani, T., Endo, K., Nara, E., Nakazora, S., Hashida, M. (1992) Effect of chronic administration of phenobarbital on the hepatobiliary transport of phenol red: assessment by statistical moment analysis. Pharm. Res. 9: 908-914

Kawakami, S., Horimoto, T., Nishida, K., Hirayama, R., Mukai, T., Nakashima, M., Sasaki, H., Sakaeda, T., Nakamura, J. (2002) Kidney- and site-selective delivery of 5-fluorouracil utilizing the absorption on the kidney surface in rats. Biol. Pharm. Bull. 25: 928-930

Litterst, C. L., Torres, I. J., Arnold, S., McGunagle, D., Furner, R., Sikic, B. I., Guarino, A. M. (1982) Adsorption of antineoplastic drugs following large-volume ip administration to rats. Cancer Treat. Rep. 66: 147-155

Lukas, G., Brindle, S. D., Greengard, P. (1971) The route of absorption of intraperitoneally administered compounds. J. Pharmacol. Exp. Ther. 178: 562-564 
Mukai, T., Tsurumaru, A., Mera, K., Nishida, K., Nakamura, J., Sasaki, H., Sakaeda, T. (1999) Absorption characteristics of model drugs from the gastric serosal surface in rats. Pharm. Pharmacol. Commun. 5: 609-614

Nakamura, J., Tsurumaru, A., Mera, K., Mukai, T., Nishida, K., Sasaki, H. (1999) Absorption of drugs applied to the gastric serosal surface in rats. Pharm. Pharmacol. Commun. 5: $519-522$

Nakamura, J., Horimoto, T., Hirayama, R., Mukai, T., Nakashima, M., Sasaki, H., Nishida, K. (2003) Effect of the absorption enhancer saponin on the intrarenal distribution of 5fluorouracil following its kidney surface application in rats. Biol. Pharm. Bull. 26: 10491051

Nishida, K., Tonegawa, C., Kakutani, T., Hashida, M., Sezaki, H. (1989) Statistical moment analysis of hepatobiliary transport of phenol red in the perfused rat liver. Pharm. Res. 6: $140-146$

Nishida, K., Sato, N., Sasaki, H., Nakamura, J. (1994) Absorption of organic anions as model drugs following application to rat liver surface in-vivo. J. Pharm. Pharmacol. 46: 867870

Nishida, K., Sato, N., Sasaki, H., Nakamura, J. (1995a) Effect of albumin on the absorption of phenol red, bromphenol blue and bromosulphonphthalein as model drugs from the liver surface membrane in rats. Biol. Pharm. Bull. 18: 1548-1550

Nishida, K., Sato, N., Sasaki, H., Nakamura, J. (1995b) Mechanism for drug absorption from rat-liver surface membrane: effect of dose and transport inhibitors on the pharmacokinetics of phenol red. J. Pharm. Pharmacol. 47: 227-231

Nishida, K., Sato, N., Sasaki, H., Nakamura, J. (1996) Absorption characteristics of dextrans with different molecular weights from the liver surface membrane in rats: implications for targeting to the liver. J. Drug Target. 4: 141-150 
Nishida, K., Sato, N., Nakakoga, Y., Mukai, T., Sasaki, H., Nakamura, J. (1997) Effect of application volume and area on the absorption of phenol red, as a model drug, from the liver surface in rats. J. Pharm. Pharmacol. 49: 976-980

Nishida, K., Nose, S., Kuma, A., Mukai, T., Kawakami, S., Nakashima, M., Sasaki, H., Sakaeda, T., Nakamura, J. (2002) Absorption characteristics of model compounds with different molecular weights from the serosal caecal surface in rats. J. Pharm. Pharmacol. 54: $1005-1009$

Schanker, L. S., Tocco, D. J., Brodie, B. B., Hogben, C. A. M. (1958) Absorption of drugs from the rat small intestine. J. Pharmacol. Exp. Ther. 123: 81-88

Yamaoka, K., Nakagawa, T., Uno, T. (1978) Statistical moments in pharmacokinetics. J. Pharmacokinet. Biopharm. 6: 547-558 
Table 1 Recovery (\% of dose) of PSP at $6 \mathrm{~h}$ after application to the rat mesenteric surface under several application conditions at a dose of $1 \mathrm{mg}$

\begin{tabular}{|c|c|c|c|c|c|c|c|}
\hline \multirow{2}{*}{$\begin{array}{l}\text { Application } \\
\text { condition }\end{array}$} & \multirow{2}{*}{$\begin{array}{l}\text { Diffusion } \\
\text { cell }\end{array}$} & \multicolumn{3}{|c|}{ Bile } & \multicolumn{3}{|c|}{ Urine } \\
\hline & & Total & Free & Metabolite & Total & Free & Metabolite \\
\hline \multicolumn{8}{|c|}{ Mesentery without blood vessel } \\
\hline $\begin{array}{l}\text { without } \\
\text { PE cap }\end{array}$ & $\begin{array}{l}16.4 \\
\pm 2.8\end{array}$ & $\begin{array}{l}40.6 \\
\pm 2.4\end{array}$ & $\begin{array}{l}24.0 \\
\pm 2.1\end{array}$ & $\begin{array}{l}16.6 \\
\pm 1.8\end{array}$ & $\begin{array}{l}34.9 \\
\pm 1.8\end{array}$ & $\begin{array}{l}22.8 \\
\pm 3.3\end{array}$ & $\begin{array}{l}12.1 \\
\pm 2.2\end{array}$ \\
\hline $\begin{array}{l}\text { with } \\
\text { PE cap }\end{array}$ & $\begin{array}{l}91.7 \\
\pm 0.5\end{array}$ & N.D. & N.D. & N.D. & N.D. & N.D. & N.D. \\
\hline \multicolumn{8}{|c|}{ Mesentery with blood vessel } \\
\hline $\begin{array}{l}\text { without } \\
\text { PE cap }\end{array}$ & $\begin{array}{r}7.9 \\
\pm 1.9\end{array}$ & $\begin{array}{l}45.3 \\
\pm 4.2\end{array}$ & $\begin{array}{l}24.7 \\
\pm 1.5\end{array}$ & $\begin{array}{l}20.7 \\
\pm 2.7\end{array}$ & $\begin{array}{l}38.0 \\
\pm 3.3\end{array}$ & $\begin{array}{l}21.7 \\
\pm 3.5\end{array}$ & $\begin{array}{l}16.3 \\
\pm 1.0\end{array}$ \\
\hline $\begin{array}{l}\text { with } \\
\text { PE cap }\end{array}$ & $\begin{array}{l}33.1 \\
\pm 5.3\end{array}$ & $\begin{array}{l}32.4 \\
\pm 4.0\end{array}$ & $\begin{array}{l}20.3 \\
\pm 2.3\end{array}$ & $\begin{array}{l}12.1 \\
\pm 1.8\end{array}$ & $\begin{array}{l}28.2 \\
\pm 1.6\end{array}$ & $\begin{array}{l}17.3 \\
\pm 1.2\end{array}$ & $\begin{array}{r}11.0 \\
\pm 1.1\end{array}$ \\
\hline
\end{tabular}

Each value is mean \pm s.e. of at least four experiments.

N.D. : not detected. 
Table 2 Moment parameters of PSP after application to the rat mesenteric surface under several application conditions at a dose of $1 \mathrm{mg}$

\begin{tabular}{|c|c|c|c|c|c|c|}
\hline $\begin{array}{l}\text { Application } \\
\text { condition }\end{array}$ & $\begin{array}{c}\mathrm{AUC}_{\mathrm{p}} \\
\left(\mu \mathrm{g} \min \mathrm{mL}^{-1}\right)\end{array}$ & $\begin{array}{l}\mathrm{MRT}_{\mathrm{p}} \\
(\mathrm{min})\end{array}$ & $\begin{array}{c}A U C_{b, f} \\
(\mu g)\end{array}$ & $\begin{array}{l}\mathrm{MRT}_{\mathrm{b}, \mathrm{f}} \\
(\mathrm{min})\end{array}$ & $\begin{array}{c}\mathrm{AUC}_{\mathrm{b}, \mathrm{m}} \\
(\mu \mathrm{g})\end{array}$ & $\begin{array}{c}\mathrm{MRT}_{\mathrm{b}, \mathrm{m}} \\
\text { (min) }\end{array}$ \\
\hline \multicolumn{7}{|c|}{ Mesentery without blood vessel } \\
\hline $\begin{array}{l}\text { without } \\
\text { PE cap }\end{array}$ & $\begin{array}{l}573.1 \\
\pm 29.7\end{array}$ & $\begin{array}{l}220.2 \\
\pm 25.7\end{array}$ & $\begin{array}{l}271.4 \\
\pm 21.4\end{array}$ & $\begin{array}{r}183.7 \\
\pm 8.8\end{array}$ & $\begin{array}{l}196.1 \\
\pm 22.9\end{array}$ & $\begin{array}{r}205.9 \\
\pm 9.6\end{array}$ \\
\hline $\begin{array}{l}\text { with } \\
\text { PE cap }\end{array}$ & N.C. & N.C. & N.C. & N.C. & N.C. & N.C. \\
\hline \multicolumn{7}{|c|}{ Mesentery with blood vessel } \\
\hline $\begin{array}{l}\text { without } \\
\text { PE cap }\end{array}$ & $\begin{array}{l}493.7 \\
\pm 61.1\end{array}$ & $\begin{array}{l}177.0 \\
\pm 26.1\end{array}$ & $\begin{array}{l}269.1 \\
\pm 16.5\end{array}$ & $\begin{array}{l}158.1 \\
\pm 18.8\end{array}$ & $\begin{array}{l}229.0 \\
\pm 29.2\end{array}$ & $\begin{array}{l}175.4 \\
\pm 17.7\end{array}$ \\
\hline $\begin{array}{l}\text { with } \\
\text { PE cap }\end{array}$ & $\begin{array}{l}326.7 \\
\pm 53.7\end{array}$ & $\begin{array}{l}171.9 \\
\pm 17.0\end{array}$ & $\begin{array}{l}240.2 \\
\pm 24.5\end{array}$ & $\begin{array}{l}208.7 \\
\pm 15.8\end{array}$ & $\begin{array}{l}145.2 \\
\pm 21.3\end{array}$ & $\begin{array}{l}218.5 \\
\pm 14.3\end{array}$ \\
\hline
\end{tabular}

N.C.: not calculated because of undetectable PSP concentrations in the plasma and bile.

Each value is mean \pm s.e. of at least four experiments. 


\section{Figure captions}

Figure 1 Experimental method for drug application to the rat mesenteric surface

A cylindrical diffusion cell made of glass (i.d. $6 \mathrm{~mm}$, area $0.28 \mathrm{~cm}^{2}$ ) was employed to selectively study the absorption of a drug from the rat mesenteric surface. The diffusion cell was attached to the rat mesenteric surface without or with blood vessels as illustrated by a dotted circle (A) and a circle (B), respectively, using Aron Alpha biocompatible glue in the hatched region. In some experiments, a polyethylene cap (PE cap) was attached on the other side to block the diffusion of the drug absorbed across the mesenteric surface. All dimensions are approximate.

Figure 2 Plasma concentration profiles of free PSP after application to the rat mesenteric surface without (A) or with blood vessel (B) at a dose of $1 \mathrm{mg}$

Key: $\quad$; Without PE cap $\quad \bigcirc$; With PE cap. $\quad$ Each point represents the mean \pm s.e. of at least four experiments.

Figure 3 Biliary excretion rate profiles of free PSP and its metabolite after application to the rat mesenteric surface without (A) or with blood vessel (B) at a dose of $1 \mathrm{mg}$ Key: Without PE cap (free PSP $\mathbf{O}$, PSP metabolite $\bigcirc$ ), With PE cap (free PSP $\boldsymbol{\Delta}$, PSP metabolite $\triangle$ ). Each point represents the mean \pm s.e. of at least four experiments. 
Figure 1

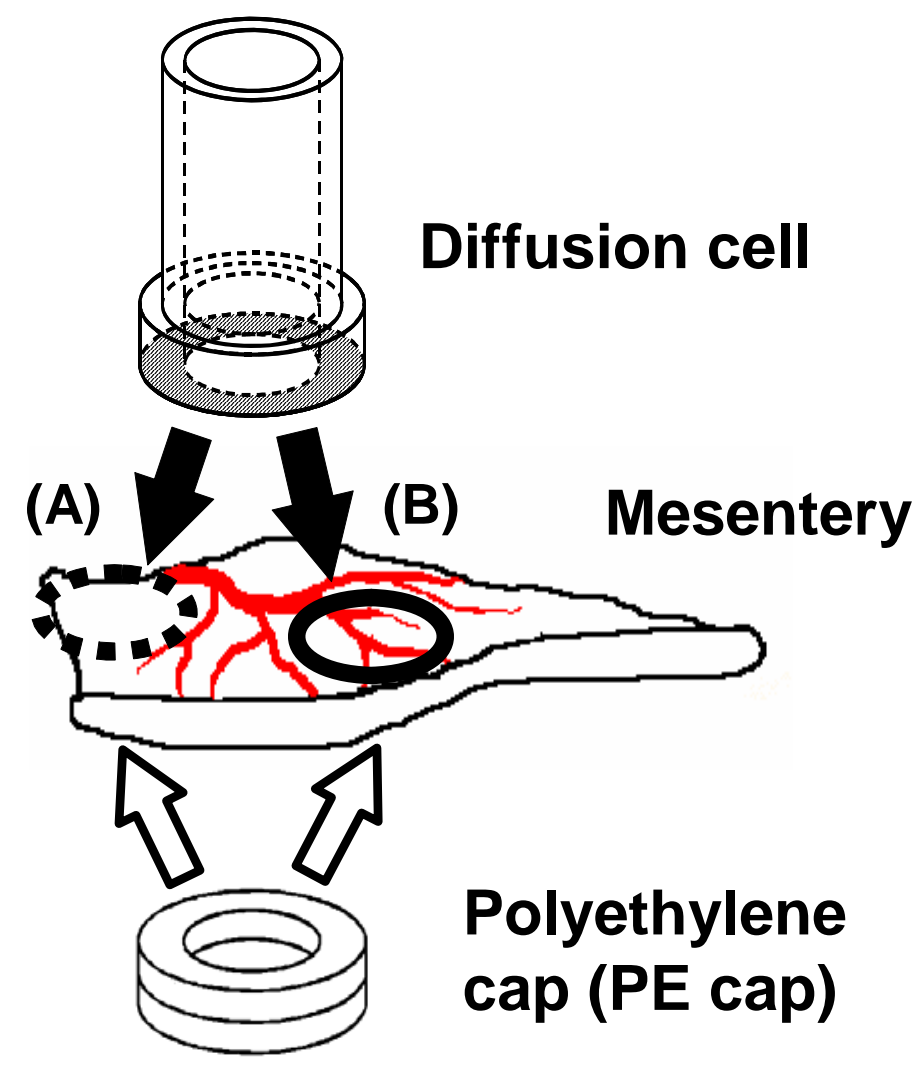


Figure 2
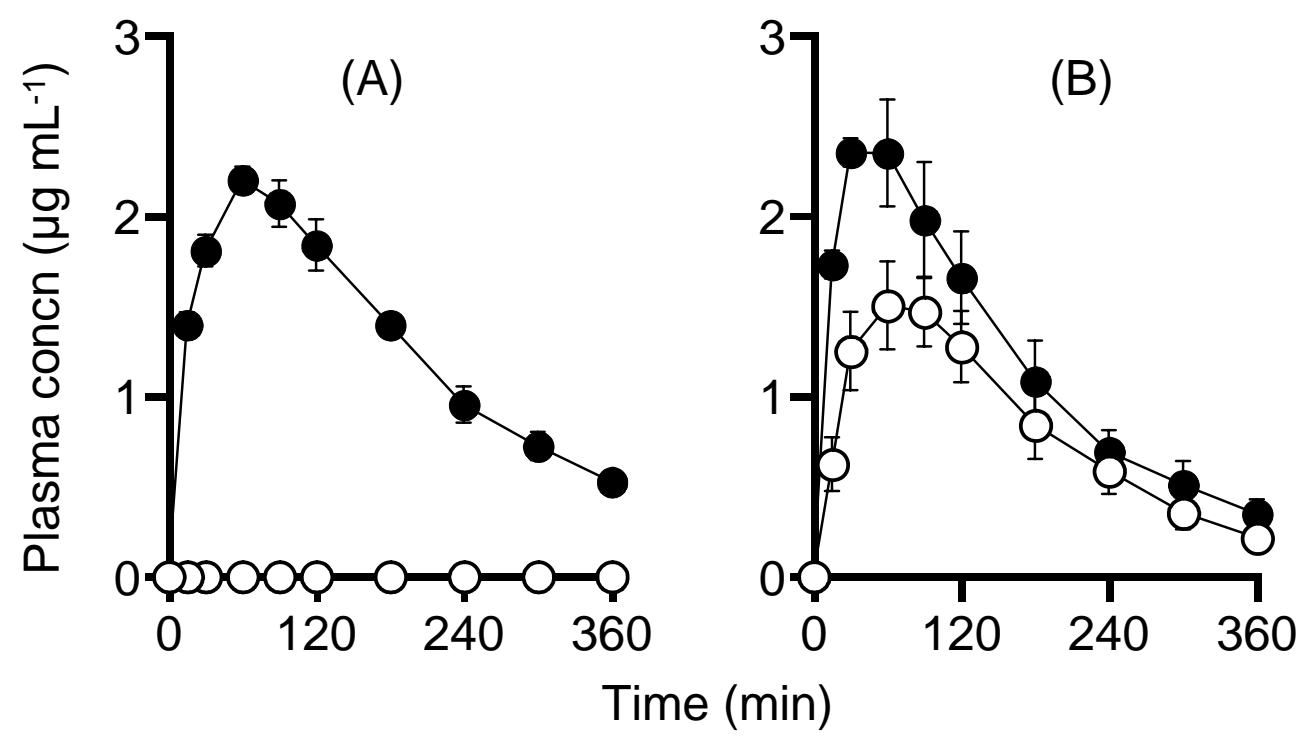
Figure 3
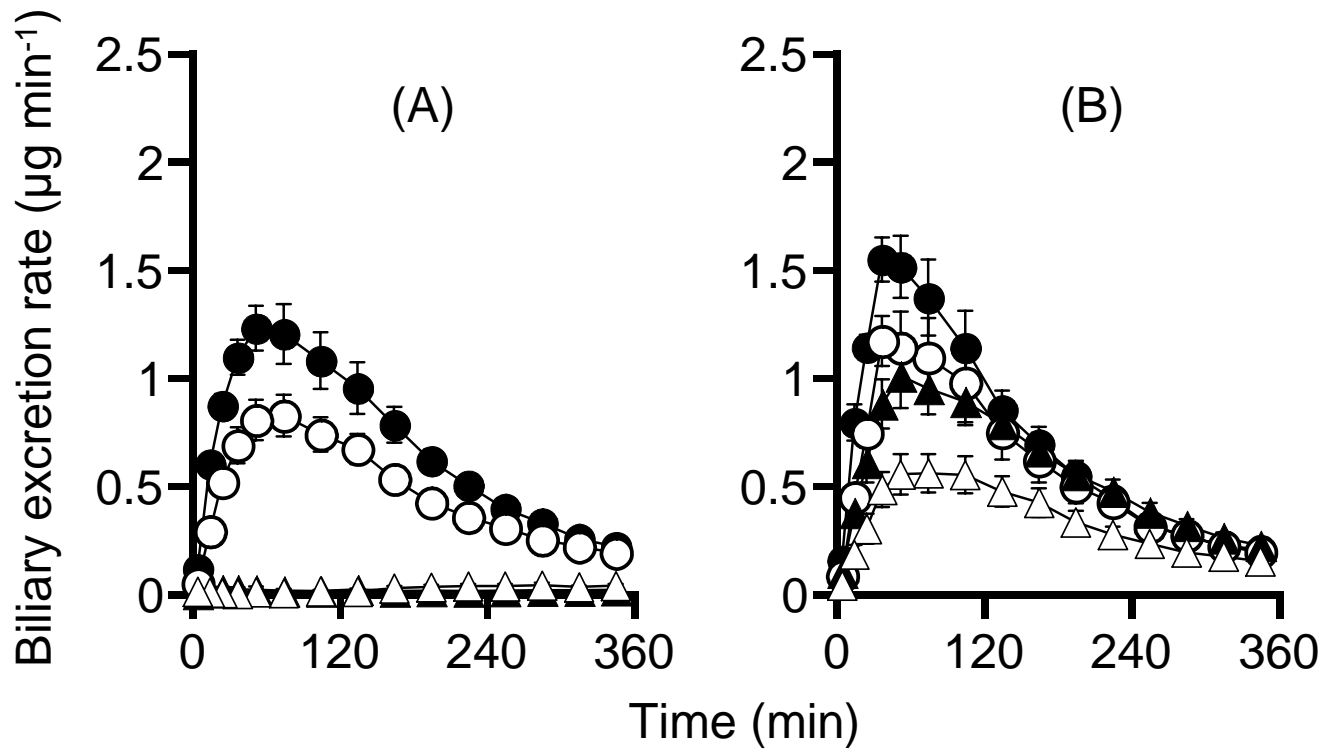